\title{
OS ELOS PERDIDOS: A ATUAÇÃO FEMININA NA DIPLOMACIA LUSO-BRASILEIRA, 1780-1822
}

\section{Resumo}

Os estudos diplomáticos nas últimas décadas passaram por uma evolução significativa. Parte desse ajuste veio por intermédio dos estudos de gênero, que romperam com a análise formalista que vigorava até então. Este artigo é um primeiro passo para estudar um grupo específico de mulheres associadas à diplomacia em Portugal e no Brasil. A despeito de serem formalmente excluídas do mundo formal da profissão diplomática, elas exerceram papel de relevo no início do século XIX. Argumentar-se-á que isso foi realizado por intermédio do papel que exerciam nas cortes e em decorrência da escassa divisão de gênero no espaço entre trabalho e lar na área diplomática.

Palavras-chave: Diplomacia, Mulheres, Portugal e Brasil, Gênero, 1780-1822.

\section{Abstract}

Missed links: feminine activities in luso-brazilian diplomacy, 1780-1822

In the last decades, the field of diplomatic studies went through a meaningful transformation. Part of this change results from the impact of gender studies, which disrupted traditional formalist analysis. This article is a first step towards the study of a specific group of women associated with diplomatic activities in Portugal and Brazil. Despite formally excluded from diplomacy, they performed important roles at the beginning of the $19^{\text {th }}$ century. I will argue that this success was a result of the role they played in royal courts and the lack of a gendered division between work and home environments in the diplomatic arena.

Keywords: Diplomacy, women, Portugal and Brazil, Gender, 1780-1822.

\section{Resumen}

Enlaces perdidos: actividades femeninas en la diplomacia luso-brasileña, 1780-1822

En las últimas décadas el campo de los estudios diplomáticos pasó por una transformación significativa. Parte de este cambio se debe al impacto de los estudios de género, que sobrepasarán el análisis formalista tradicional. Este artículo es un primer paso hacia el estudio de un grupo específico de mujeres asociadas a actividades diplomáticas en Portugal y Brasil. A pesar de su exclusión formal de la diplomacia, ellas desempeñaron importantes funciones a principios del siglo XIX. Argumentaré que este éxito fue el resultado del papel

\footnotetext{
Pesquisador associado do Instituto de Relações Internacionais da Universidade de Brasília, Brasília-DF, 70904-970. Brasil.

Endereço postal: Instituto de Relações Internacionais. Campus Universitário Darcy Ribeiro Prédio do Ipol/Irel s/n — Asa Norte, Brasília-DF, 70904-970. Brasil.

Endereço eletrônico: rofarias@gmail.com

ORCID: https: / / orcid.org/ 0000-0001-6678-0984
} 
que tuvieron en las cortes reales y de la falta de una división de género de la segregación espacial entre el trabajo y lo ámbito doméstico en la diplomacia.

Palabras-clave: Diplomacia, mujer, Portugal y Brasil, Género, 1780-1822.

\section{Introdução}

Desde a década de 1990, a área de relações internacionais tem apresentado enfoques com inovadores olhares para o estudo do sistema internacional. A abordagem de gênero é um dos mais importantes, particularmente na discussão do tema estatuto e hierarquia (Denéchère 2004; James 2015; Garner 2018, 251-267). Isso resulta de uma preocupação que busca, entre outros objetivos, questionar quem são e onde estão as mulheres, e como as estruturas masculinas hegemônicas conformam a reprodução das práticas sociais da política internacional (Zalewski 2010, 31-32).

Contribuindo para essa literatura, neste artigo argumenta-se que um grupo específico de mulheres em Portugal e no Brasil, a despeito de ser formalmente excluído das atividades diplomáticas, exerceu papel de relevo nesse domínio por múltiplas vias. Desse modo, as relações internacionais não podem ser compreendidas em seu aspecto estritamente político e socioespacial sem o recurso ao estudo do papel feminino. O objetivo nesse texto é focar no que se pode considerar como espaço feminino de exercício informal de poder diplomático - a sociedade de corte e o ambiente dos salões e do lar (McCarthy 2015, 167).

Este artigo, assim, dá um primeiro passo para que seja possível examinar, no futuro, no mundo diplomático português e brasileiro, o processo em que as atitudes com relação às mulheres na elite se vincularam ao mecanismo social de hierarquização da sociedade internacional (Towns 2010, 4-7). A adesão à prática diplomática em voga constituía uma sinalização de status de civilização. Dessa forma, o espaço concedido às (e conquistado pelas) mulheres nesse âmbito buscava reposicionar duas sociedades periféricas (brasileira e portuguesa) no sistema internacional. A mulher ligada à diplomacia tornou-se, nesse contexto, um estandarte da projeção de uma sociabilidade refinada, instrumental para a sinalização de superação de atraso e de conquista de uma igualdade simbólica em um mundo estatal hierárquico - algo distinto do movimento mais generalizado no século XIX que legava status simbólico civilizado à marginalização feminina (Towns 2009).

Dessa maneira, era esperado das mulheres associadas aos diplomatas o aprendizado das regras informais que permeavam a sociabilidade cotidiana das cortes e lhes legava um papel relativamente proativo. Essa educação servia de capital para melhor se posicionarem socialmente e de canal de transmissão das práticas cotidianas da elite das grandes capitais europeias para a periferia do sistema internacional. As redes de relacionamentos e as práticas sociais vinculadas à criação e à manutenção de salões literários e à casa do diplomata constituíram, assim, via de aproximação junto às rotinas sociais cosmopolitas. Nesses ambien- 
tes, elas exerciam relativo poder de agência e influência, algo permitido segundo as práticas consideradas mais avançadas no estertor do Antigo Regime. Por outro lado, ao usarem esse capital simbólico como forma de manutenção de status no plano doméstico, ajudavam a reproduzir a hierarquização estrutural do sistema internacional em suas próprias sociedades. ${ }^{1}$

\section{A mulher na diplomacia do Antigo Regime}

Qual era o papel da mulher na diplomacia europeia do Antigo Regime? Havia diversas situações que as habilitaram a ter influência nas relações internacionais. A primeira tem que ver com a posição que algumas tiveram como princesas, regentes e rainhas. No caso de Portugal e do Brasil, a literatura explora o papel de princesas e rainhas, ainda que sem inserir essas figuras na literatura sobre estudos diplomáticos. A segunda, pouco explorada, refere-se ao papel de mulheres que adquiriram seu status em decorrência de sua vinculação com a «casa do embaixador» e o ambiente da corte, uma dimensão redescoberta nas últimas décadas na área de estudos diplomáticos, sendo o foco de nossa análise.

Até o século XVII, era pouco comum que embaixadores e ministros plenipotenciários fossem acompanhados pelos seus familiares em missões no exterior (Allen 2019). Há variação com relação a países e a períodos, sem contar a própria definição do que pode ser caracterizado como participação feminina, mas no século XVIII elas já integravam o mundo diplomático das cortes europeias. Destaca-se, em especial, nesse período de transição, o papel das embaixatrizes. Uma prova desse avanço são os numerosos guias de recomendação cerimonial da época, recheados de instruções sobre como se portar em eventos sociais (Dumont e Rousset 1739, 50-59). Moser, ao apresentar o caráter essencial da atividade da embaixatriz para o sucesso de uma missão diplomática, recomendava ao diplomata que confidenciasse informações para sua esposa, de maneira que ela pudesse assessorá-lo (Moser 1752, 159-167).

Portugal era um dos países com menor número de representes diplomáticos no exterior $-2 \%$ das missões permanentes ou temporárias totais da Europa (Roosen 1978, 3, 6). Como a maioria eram embaixadores extraordinários, com missões mais curtas e temporárias, seria natural que os chefes de missão levassem somente secretários. A presença de membros de ordens religiosas como membros de missão reduzia ainda mais a possibilidade de deslocamento feminino, pois como não tinham esposas nem filhas, nesses casos não existiam canais para mulheres exercerem papéis proativos no domínio diplomático (Monteiro, Cardim, e Felismino 2005). O diplomata português Francisco de Sousa Coutinho, atuando

Sobre os rituais da corte no Brasil e a busca por um padrão de civilização, ver Malerba (2000, 82-89). 
na Holanda em 1643, talvez tenha sido o primeiro após a Restauração a observar a mudança do padrão internacional. Ele relatou que a elite local duvidou de seu caráter permanente de representante da coroa portuguesa por não estar com sua esposa - os diplomatas no país estavam acompanhados de cônjuges e perguntavam repetidamente onde estava a sua. Pediu, então, autorização ao rei em Lisboa para sua esposa ir para a Holanda (Prestage e Azevedo 1920, 11, 13). No século XVIII, as embaixatrizes já eram elemento importante das estratégias de ascensão profissional de diplomatas portugueses ambiciosos. Um caso relevante é Sebastião José de Carvalho e Melo, futuro marquês de Pombal, que casou em Viena com uma condessa austríaca dama da corte e parente do célebre marechal conde Leopoldo José von Daun, com o beneplácito da imperatriz Maria Tereza (Conde da Carnota e Fonseca e Castro 1872, 23, 25).

Não há estudo prosopográfico do grupo de esposas de diplomatas em Portugal e, depois, no Brasil, mas a evidência disponível indica que eram nobres portuguesas ou estrangeiras. No primeiro caso, estar associada à vida diplomática foi certamente uma fonte de libertação. A visão tradicional é que as mulheres, mesmo da elite, eram pouco educadas, pouco circulavam fora de casa, ocupando seu tempo com atividades domésticas, lidando com a supervisão da educação dos filhos e das atividades do lar e, quando eram alfabetizadas, limitando-se à leitura de textos de natureza religiosa (Bernardino 1986, 113-124).

Hoje, a tese de que eram reclusas, analfabetas, religiosas e sedentárias não é abrangente. Após décadas de pesquisas, há indicação de que ocorreu, a partir da segunda metade do século XVIII, lenta transição do papel da mulher, especialmente na elite portuguesa (Anastácio 2010, 97-98). Sinais dessa mudança são encontrados na redução do fluxo das mulheres da elite para clausuras religiosas e no aumento da interação com homens em ambientes controlados. ${ }^{2} \mathrm{O}$ resultado foi «maior exposição em público, maiores oportunidades para socializar tanto dentro do grupo como com membros do sexo oposto, maior oportunidade para gratificação pessoal e até maiores oportunidades de educação» (Esdaile 2014, 41-42).

No Brasil, a evolução também foi sensível. Capistrano de Abreu apontou, ao analisar a colônia, a segregação espacial por gênero no cotidiano (Capistrano de Abreu 1954, 355). No período joanino, essa foi também a interpretação de muitos viajantes. ${ }^{3}$ Ocorreu, contudo, uma evolução da historiografia. Hoje, é possível identificar que mulheres do estrato popular, incluindo escravas, tinham grande papel na circulação econômica, e mesmo mulheres da elite interagiam socialmente

\footnotetext{
2 Margarida Sobral Neto indicou a dificuldade ainda existente de «construir a síntese fundamentada sobre a sua [das mulheres] participação nos diversos níveis da realidade social» (Sobral Neto 2001, 41). Mesmo no ambiente monástico, muitas mulheres mantiveram ativa vida intelectual (Bellini 2007).

3 Exemplo em Walsh $(1831,100)$ e Luccock $(1820,111)$. Viajando pelo interior, Langsdorff encontrou a mesma situação $(1997,184,204)$.
} 
no âmbito religioso, cívico e até comercial, principalmente quando viúvas (M. B. N. Silva 1993, 13, 273; Cavalcanti 2004, 81, 172, 223; Kraay 2006, 320). ${ }^{4}$

A diplomacia inscreve-se de forma diferenciada nessa narrativa. As esposas e filhas de diplomatas viviam no contexto da sociedade de corte, e a evidência disponível demonstra que estavam longe de serem ignorantes e atavicamente religiosas. Há indicação de que provinham, em geral, de famílias que valorizavam o conhecimento, inclusive feminino. Sabiam ler e escrever, além de executar várias tarefas para assistir a missão de seus maridos. ${ }^{5}$

Talvez o caso mais emblemático que ilustra a associação feminina ao contexto diplomático seja o de Leonor de Almeida e Portugal, a marquesa de Alorna (17501839). Como bem demonstra Vanda Anastácio, ela lia em sete línguas - inclusive o latim -, o que lhe possibilitou acompanhar de perto as novidades literárias de sua época (Anastácio 2011). Sua trajetória biográfica demonstra seu poder de agência na consolidação de redes sociais próprias, através das quais se posicionou e manobrou politicamente. Primeiro, casou-se com o nobre alemão Karl-August von Oeyenhausen-Gravenburg contra a vontade de seu pai - mas com o apoio da rainha Maria I. Segundo, conseguiu que seu marido fosse designado ministro para um posto diplomático em Viena. Sua própria narrativa sobre como conseguiu este feito é relevante para identificar o exercício do poder feminino no momento crucial da vida diplomática de então - a nomeação para um posto no exterior. A condessa informou que, em 1780, se deslocou ao Paço Real de Salvaterra dos Magos. Lá, utilizou os contatos com as princesas, damas e camareira-mor para aproximarse da rainha e solicitar o favor. Recebeu uma resposta seca e evasiva. Permaneceu, contudo, nesse ambiente de corte durante um tempo, tomando «conhecimento daquele terreno, da linguagem necessária nele e dos indivíduos que compunha a casa de sua majestade». Sua principal conclusão nesse processo de observação era que «na nossa corte é preciso pedir e que de pouco ou nada serve merecer». Partiu, então, para a batalha. Isso envolveu atuar na rede de intrigas do paço e ser extremamente obstinada - «me propus não sair sem arrancar meu marido à situação penosa em que se achava». O interessante desse processo é que a coalizão de forças a favor de sua pretensão era predominantemente feminina, enquanto seus inimigos, particularmente o visconde e o marquês de Angeja e o arcebispo de Tessalônica, eram homens (Cidade 1941, 60-68). Ela acabou obtendo sucesso.

Leonor de Almeida e Portugal acompanhou seu marido na missão em Viena, que durou cinco anos (1780-1785), residindo depois na França. Em uma carta escrita no início de sua vida diplomática, compartilhou: «As diversas gentes, os

Ainda há, no entanto, muitos que indicam a predominância da reclusão. Ver, por exemplo, Tostes (2008).

Inexistem estudos prosopográficos específicos sobre esse período, especialmente no período do Antigo Regime. Vários trabalhos, no entanto, apresentam essas características em casos específicos. Ver, por exemplo, Allen (2019) e James e Sluga (2015). 
costumes diversos, tudo tem aumentado consideravelmente o número de minhas ideias» (apud Anastácio 2017, 135-136). Ao retornar a Portugal com essas novas ideias, reproduziu em sua residência os salões que frequentava em Viena. Nesse contexto, tornou-se um elo entre a sociedade ilustrada portuguesa e as práticas sociodiplomáticas de Viena, reunindo ao seu redor romancistas e poetas, trazendo e debatendo as últimas novidades literárias das capitais europeias (Carvalho 1898, 68-69; Anastácio 2010, 93; Andrade 2011, 212-213). Seu perfil aristocrático, sua experiência em Viena, sua extensa rede de contatos e a habilidade política levou à sua nomeação para dama de honra de Carlota Joaquina. Ela inundava a elite política de correspondência, redigindo até uma memória «sobre a situação internacional de Portugal», com «sugestões sobre os seus remédios», ao príncipe regente D. João VI (Cidade 1941, 127). Não é possível saber como foram recebidas suas sugestões neste caso, mas sabe-se de pelo menos um caso em que incomodou os homens de sua época. Quando residiu em Londres, durante as guerras napoleônicas, Lord Strangford reclamou ao ministro português da incômoda situação: ela «apanhou um jeito terrível de me escrever longas cartas, e eu julgo que pensa que eu não tenho mais que fazer do que responder-lhe» (apud Pereira 1956, 57). Esse tipo de reclamação não era pontual nas cortes europeias. Charles J. Esdaile relata que, na Espanha, o Diario Mercantil de Cádiz informou seus leitores do facto de os ambientes de exercício do poder político estarem inundados de mulheres que se tornaram intermediárias profissionais na atividade de buscar favores (Esdaile 2014, 143).

As filhas de diplomatas estavam no centro das estratégias de ascensão social da nobreza no Antigo Regime. As questões, muitas vezes, tinham desdobramentos cruéis. Na época pombalina, Izabel Juliana de Souza Coutinho, filha de Vicente de Souza Coutinho, representante português em Paris e chefe de uma das casas mais ricas do reino, foi designada pela família para casar com o filho do Marquês de Pombal, mas logo rebelou-se. Por três anos batalhou contra o matrimônio. O primeiro-ministro aquiesceu ao divórcio, mas obrigou sua ex-nora a entrar para um convento. Viveu enclausurada por oito anos, até a morte do rei D. José (Carvalho 1898, 13-21). Casou-se, posteriormente, com um diplomata - Alexandre de Sousa e Holstein, primeiro representante português na Prússia.

O caso de Izabel Juliana é atípico, mas longe de ser único. Luísa Margarida Portugal de Barros (1816-1891), filha de Domingos Borges de Barros, o visconde da Pedra Branca, um dos mais relevantes diplomatas brasileiros do Império, foi criada e educada em Paris. Fluente em várias línguas e tendo conhecido vários países, seu pai desejava casá-la com Miguel Calmon du Pin e Almeida, o futuro marquês de Abranches. Ele queixou-se a um colega que Luísa rejeitara o noivado porque vivia desde criança na França e não desejava sair do país. «Seus hábitos, suas relações e afeições são da pátria de educação, e que do Brasil mui fracas são as memórias». Seu pai estava devastado: «Sofri muito e sofro ainda. [...] Se V. E. tiver filha, não a eduque fora da pátria», afirmou (apud Meneses 1917, 481-482). 
A ponderação indica que a formação no exterior de sua filha deu-lhe indesejada independência, aos olhos de seu pai. Mas Luísa soube definir sua própria estratégia matrimonial e, acima de tudo, posicionar-se na corte imperial brasileira ao casar-se com o conde francês Eugênio de Barral. Quando a princesa de Joinville, irmã de D. Pedro II, se mudou para a França, precisava da competência técnica de uma pessoa que conhecesse a corte francesa e Luísa foi escolhida para a tarefa, sendo nomeada dama do Paço pelo rei da França.

Foi em decorrência de seu elo com a princesa de Joinville que retornou ao Brasil em colocação de destaque. Após negociar arduamente sua remuneração e cargo, deixou seu marido temporariamente na Europa e retornou ao Brasil em 1847 para ocupar-se da supervisão da educação de Isabel Cristina e Leopoldina Teresa, filhas de D. Pedro II. Sua função, no entanto, extrapolava essas atividades, pois seu conhecimento e rede de contatos com nobres e intelectuais europeus foi colocada ao serviço do rei, uma personalidade com muito interesse em ser visto como monarca ilustrado, na vanguarda de um processo civilizatório, seguindo os padrões europeus em voga então (Priori 2008a). Percebe-se, assim, que tanto na França como no Brasil ela desempenhou um nicho de atividades voltadas para inserir seus empregadores de forma menos subalterna na hierarquia do sistema simbólico das cortes.

Depreende-se desses relatos que é impossível compreender o papel da mulher na diplomacia sem considerar as redes familiares em que estavam inseridas. Era por intermédio delas que adquiriam o aprendizado aristocrático, batalhavam por posição social e mantinham e expandiam seu capital político para avançar os interesses de suas famílias. Diante das demandas que tal posição social exigia, foi natural que muitos diplomatas casassem entre si, criando verdadeiramente uma rede paralela de informações.

\section{A ação obscura}

Até aqui indicamos o papel de mães e filhas de diplomatas. Não adentramos no tópico de outras personalidades e até a influência propriamente dita das mulheres na diplomacia. Sobre o primeiro aspecto, convém examinar a figura misteriosa de Suzanne Célie Cappadoce-Pereira. Sabe-se que nasceu em Paris, era poliglota e grande intelectual. Casada com um financista e cônsul português na Dinamarca nascido em Amsterdão, serviu a Antônio de Araújo e Azevedo, futuro conde da Barca, como tradutora na Holanda. Segundo Jean de Pins, tornou-se amante de Araújo (e de seu sucessor), abrindo as portas da elite política e financeira de Paris para os portugueses, atuando inclusive para aproximar-se do conde de Ega como forma de obter informação sobre a movimentação militar dos espanhóis e afastar Napoleão de uma aliança com Madrid (Pins 1976, 123). 
Essa atuação tão ostensiva talvez tenha sido minoritária. A presença feminina na diplomacia desenrolava-se principalmente no âmbito da residência do diplomata. Hoje, há grande distância social e espacial entre o mundo do trabalho e o mundo da família. No passado, porém, o domicílio do diplomata era espaço preferencial de exercício diplomático. Isso envolvia eventos - recepções, jantares e encontros - e, naturalmente, a própria secretaria da missão. É nesse contexto que se observa a ação cotidiana da mulher na diplomacia luso-brasileira.

De facto, a análise desse ambiente ajuda a desmistificar a suposta opulência do cotidiano social da profissão no período. Tanto pelas condições resultantes das guerras napoleônicas como pela fragilidade fiscal de Portugal e Brasil, nas décadas de 1820 e 1830, eram elevadas as dificuldades cotidianas no exterior. Isso, em pelo menos um caso, elevou a relevância da atuação feminina. Em 1825, Domingos Borges de Barros relatou que, em decorrência da exiguidade de recursos e do volume de trabalho, teria adotado «a economia a ponto de ser minha mulher [Maria do Carmo] o Secretário da Legação por muito tempo, como aí se verá dos papeis e contas, por ela escritas». Ela havia se despido «de seus enfeites e joias para memozear pessoas que convém aliciar em bem do Império», correndo toda a cidade de Paris em busca de produtos mais baratos e, mesmo assim, a família sofria grandes prejuízos financeiros - sua esposa também cuidava minuciosamente da contabilidade (apud Ministério das Relações Exteriores 1972 [1922], 260; Priori 2008b, 152). O peculiar do caso é que a descrição das atividades de sua mulher aponta que atuou fora do ambiente doméstico para resolver problemas financeiros, o que desafia a tese mais generalizada sobre gênero e diplomacia de que a mulher exercia influência, mas limitada ao lar (Kühnel 2017, 131).

O exame da vida de Gabriela Asinari di San Marsan, esposa de D. Rodrigo de Souza Coutinho, talvez ofereça a contribuição analítica mais relevante nesse conturbado período por transitar de uma vida em um posto diplomático (Legação em Turim) para Lisboa e, depois, para o Brasil. O primeiro aspecto a ser notado é o facto de ser estrangeira - muitos diplomatas portugueses casavam com mulheres ligadas às cortes em que atuavam, a maioria oriunda da nobreza. Isso possibilitou integrar tais representantes em uma rede de relacionamentos transnacionais e ajudava tanto suas missões no exterior como elevava o respectivo status em Lisboa. A segunda questão que merece nota é o facto de ter deixado amplo acervo de correspondência, o que permite estudar seu cotidiano (Araújo 2018). Como se observará, esse material é essencial para compreender a inserção de Portugal na complexa ordem política internacional do período joanino.

A primeira atuação de Gabriela foi em sua terra natal, na facilitação dos contatos de seu marido na corte local. Essa atuação durou de 1789 a 1897, quando D. Rodrigo foi chamado a Lisboa para ocupar o cargo de presidente do Real Erário. Ele partiu sozinho, deixando sua família em Turim. Gabriela, nessa circunstância, exerceu o crucial papel de manter as relações sociais e de coletar informações políticas. Ela organizava sua secretaria pessoal, inclusive seus documentos con- 
fidenciais, e manteve-o a par dos desenvolvimentos políticos e militares do norte da Itália (Araújo 2018, 284-286). Isso se estende até para as que permaneciam em Lisboa (e posteriormente no Rio de Janeiro), enquanto seus maridos ocupavam postos no exterior. Eugénia da Gama, futura duquesa de Palmela, em certa oportunidade relatou a seu marido a pesada rotina social que tinha na cidade: «Todos os dias comem cá em casa mais de trinta pessoas» (Carvalho 1898, 390). Essas ocasiões permitiam realizar a defesa constante das atividades diplomáticas de seu marido junto à elite local e coletar informações políticas cruciais sobre a instável situação portuguesa no contexto das guerras napoleônicas - algo essencial para o desempenho das atividades diplomáticas de seu marido, então residindo em Londres. ${ }^{6}$

O estudo da ação de Gabriela San Marsan é oportuno por ela ter deixado grande volume de correspondência, tanto para familiares de seu marido como para diplomatas portugueses. Após 1807, essas fontes constituem uma janela para compreender o papel da mulher no cotidiano da secretaria de Negócios Estrangeiros no Brasil. Um de seus primeiros relatos de interesse é a travessia de 77 dias pelo Atlântico a bordo do navio Príncipe do Brasil (A. M.-D. Silva 2006, 578-595. Após a chegada ao Rio de Janeiro, seu marido, D. Rodrigo da Souza Coutinho, foi nomeado ministro dos Negócios Estrangeiros e da Guerra. Gabriela participou da montagem da repartição em sua própria residência, perto do Passeio Público e da Glória. O regime de trabalho era pesado para a época. As poucas pausas eram para audiências. Gabriela, testemunha e participante desses eventos, provavelmente pelo protocolo mais informal da corte no Rio de Janeiro e pelos distúrbios causados pelos conflitos napoleônicos, acreditava que havia maiores facilidades para a solicitação de despachos junto ao ministro (A. M.-D. Silva 2006, 213, 585). A escassez de pessoal de apoio e o volume de trabalho acabou levando à sua atuação na manutenção de contatos com diplomatas portugueses no exterior.

Um dos principais interlocutores de Gabriela foi João Paulo Bezerra de Seixas, diplomata português com passagens pelos Estados Unidos da América, pela Holanda e pela Rússia. É impressionante o volume de informações diplomáticas que trafega no diálogo epistolar entre ambos. Em francês, ele relata questões financeiras e políticas delicadas, inclusive a sutil tentativa de subornar Hipólito da Costa, o autor do Correio Braziliense. ${ }^{7} \mathrm{O}$ tom das confidências, sentimental e voltado muitas vezes para o desabafo, denota a construção de uma imagem de sua interlocutora muito comum na época - a de receptáculo terapêutico de frustrações e fonte de suporte emocional. A atuação da condessa, contudo, demonstra como

A documentação epistolar está disponível para consulta, em microfilme, predominantemente no fundo PT / TT / CPLM / B. O volume de Carvalho (1898) conta com várias transcrições úteis para compreender suas atividades no contexto da diplomacia portuguesa.

7 De Bezerra de Seixas para Gabriella de Souza Coutinho. Londres, 7 de março de 1810. PT/TT/ $\mathrm{CLNH} / 0086 / 02$. 
fazia uso estratégico do estereótipo de gênero para avançar seus objetivos pessoais (James e Sluga 2015, 5). O mais importante para nossos propósitos são os insistentes pedidos de notícias por parte de Bezerra sobre a política de bastidores de intrigas da realeza no Brasil e as insistentes solicitações por favores («mes petits intérêts personnels», nas próprias palavras de Bezerra). ${ }^{8}$ Isso demonstra como a condessa adquiriu status privilegiado por seus canais de acesso junto ao príncipe regente e sua esposa.

Mesmo com a morte de Souza Coutinho e com a vinda de Bezerra para o Rio de Janeiro, em 1812, este continuou a manter o mesmo relacionamento com Gabriela San Marsan. A razão decorre dos relacionamentos que a condessa tinha na corte. Já com o título de condessa de Linhares, foi nomeada camareira-mor no paço imperial, o que lhe deu acesso ao centro do poder. ${ }^{9}$ A condessa de Linhares correspondia-se cotidianamente com Carlota Joaquina, com o tempo tornando-se uma confidente. Sabia, por esse canal, de várias questões que se passavam na corte e em Madrid. Em fevereiro de 1821, a rainha fez o assentamento da carta régia para nomeá-la camareira-mor da princesa real - garantido, assim, sua influência sobre a próxima geração.

Era esse acesso privilegiado que tanto interessava Bezerra, que buscava melhor posicionar sua esposa, Isabel Sill Bezerra, nos círculos íntimos da família real. Isabel e Gabriella criaram canal próprio de comunicação em inglês e em francês. Por essa correspondência sabe-se que Isabel era instada por seu marido a manter comunicação informal com João de Souza Coutinho, 2. conde de Linhares, diplomata português e filho de Gabriella, então na Sardenha. ${ }^{10}$ Após a morte de seu marido, em 1817, Isabel tornou-se figura central na corte e continuou mantendo a correspondência. Ela foi agraciada após a morte de seu marido com o título de viscondessa de Itaguaí e nomeada dama efetiva da princesa Leopoldina (a viscondessa de Santos seria primeira dama).

A condessa de Linhares também foi habilidosa em fomentar laços com a elite brasileira. Uma das amizades mais próximas foi Felisberto Caldeira Brant, futuro marquês de Barbacena, o diplomata que negociou a Independência do Brasil em Londres. Brant tornou-se um guia para os filhos da condessa. ${ }^{11}$ Esse aspecto é importante para iluminar uma das teses mais centrais da historiografia do período: a da interiorização da metrópole, sintetizando o enraizamento dos interesses portugueses transmigrados no Brasil (Dias 1986, 165). A relação entre Brant e Gabriella indica que, além das alianças matrimoniais, as mulheres ligadas

\footnotetext{
8 De Bezerra de Seixas para Gabriella de Souza Coutinho. Haia, 27 de março de 1809. PT/TT/ $\mathrm{CLNH} / 0086 / 02$.

9 Sua documentação passiva e ativa está disponível predominantemente no fundo PT/TT/CLNH.

10 De Isabel Bezerra para condessa de Linhares. 1. de maio de 1817. PT/TT/CLNH/0086/10.

11 Há várias cartas trocadas entre os dois. Ver, por exemplo, PT/TT/CLNH/0064/06 e PT/TT/ $\mathrm{CLNH} / 0066 / 07$.
} 
à diplomacia foram essenciais na construção de elos entre a elite portuguesa emigrada e a brasileira.

\section{Conclusão}

Neste artigo, buscou apresentar-se o papel da mulher na diplomacia luso-brasileira. O deslocamento e instalação em cortes estrangeiras levou à aproximação de mulheres que conhecessem os códigos sociais em que estavam inseridas. As vinculadas às casas diplomáticas (esposas e filhas) estavam bem posicionadas para ocupar tal espaço. Elas cruzavam as fronteiras entre Estados, mantinham contato cotidiano com as sociedades de corte e adquiriam o conhecimento de suas regras formais e informais. Isso abriu campo amplo de canais de influência. Pode-se dizer até que a vida diplomática exigia delas a capacidade de ler, escrever, analisar movimentações políticas e atuar para assistir a missão de seus maridos e/ou pais.

O marco temporal deste estudo coincidiu com a ascensão e o declínio dos salões europeus. As mulheres, nesses ambientes, exerciam papel fundamental na transmissão de ideias e práticas sociais (McMillan 2000, 8-13). Tanto em Lisboa como no Rio de Janeiro, há indicações de que serviam de intermediárias de uma rede transnacional que influenciou a constituição social das mulheres da elite algo não distinto do que ocorria em Viena e Paris. ${ }^{12}$ Desse modo, a salonnière vinculada à diplomacia convertia espaços privados em esfera pública e aproveitava sua rede de contatos e conhecimento sobre as novidades das capitais cosmopolitas como ativo junto à sociedade local, influenciando costumes e ideias, como seria o caso da condessa de Barral acima mencionada, no Segundo Reinado (Priori 2008a).

O caso de Leonor de Almeida e Portugal, a marquesa de Alorna, demonstra como foi o aprendizado da sociedade de corte e como foi amplamente ativa na constituição de sua própria posição social de embaixatriz, ao batalhar para a nomeação de seu marido. O conhecimento da corte austríaca e a construção de laços sociais transnacionais foi, por sua vez, essencial para ser nomeada dama de honra de Carlota Joaquina. Sua biografia também demonstra a importância que as mulheres inseridas na diplomacia tiveram na intermediação das práticas de sociabilidade ao fim do Antigo Regime. Outro exemplo é Luísa Margarida Portugal de Barros. Pelo conhecimento que tinha do funcionamento da corte francesa, foi nomeada para ser dama do paço, ajudando a princesa de Joinville a aclimatar-se no novo ambiente social. Com a vivência na corte francesa, portadora dos modos e práticas de um centro civilizacional, gabaritou-se para exercer o papel de for-

12 Sobre a atuação de salonnières no âmbito diplomático, ver Ferraguto (2016) e Mori (2015). No caso português, ver os casos de Marie-Urbano de Lima Barreto, Suzanne Cappadoce-Peireira e Marianne da Silva em Pins (1984), 79-190. 
madora da realeza brasileira em uma tentativa de elevar o perfil da corte imperial sediada no Rio de Janeiro.

O ambiente de corte deve ser examinado em paralelo com a «casa» do embaixador. Neste artigo, mostrou-se que, assim como em outros países, a mulher desempenhou papel de grande relevância no cotidiano da diplomacia em decorrência do papel doméstico que exercia. Esse é um elemento importante, pois não havia uma segmentação espacial de gênero entre a casa e o trabalho naquela época, como ocorreu posteriormente. As crises fiscais e o grande volume de trabalho sobre o aparelho diplomático português e brasileiro, contudo, criaram um conjunto de condições particulares para o exercício da ação feminina provavelmente inexistentes em outros locais. Domingos Borges de Barros teve de utilizar sua própria esposa como secretária de legação, tendo ela minutado muitos dos documentos de sua missão. No Rio de Janeiro, a condessa de Linhares, acompanhando o funcionamento da repartição dos Negócios Estrangeiro e da Guerra em seu próprio lar, atuou para manter canais informais de comunicação com diplomatas portugueses na Europa em decorrência da pesada agenda de seu marido.

O status que exerciam na sociedade de corte as tornaram especialmente relevantes para as estratégias de ascensão familiares por intermédio da política de matrimônios. Mostrou-se aqui que as experiências de vida singular de algumas dessas mulheres tornaram-nas resistentes a seguir o curso das estratégias matrimoniais de suas casas, demonstrando grande desejo de independência. Algumas dessas decisões foram positivas. O cálculo político, contudo, não foi sempre certeiro. Juliana Maria de Oyenhausen e seu marido apostaram em Napoleão e acabaram afastados da corte portuguesa.

Neste artigo, argumentou-se que, mesmo na hipótese de não terem exercido influência significativa, o estudo das mulheres ligadas à diplomacia é importante, pois as fontes epistolares deixadas por elas são essenciais para compreender as motivações dos principais decisores e o cotidiano do poder. A extensa documentação deixada pela primeira condessa de Linhares é um claro exemplo nesse sentido.

Considerando que esta contribuição foi só uma abordagem preliminar de uma agenda de pesquisa muito ampla e ainda pouco explorada, quais são os próximos passos? O primeiro é certamente empírico. O grupo das mulheres e filhas de diplomatas não foi delimitado, de maneira que não é possível saber se os exemplos encontrados fazem parte de um padrão geral ou são exceções. Como Nuno Gonçalo Monteiro afirmou, a nobreza em Portugal era peculiar no âmbito europeu pela elevada proporção de mulheres da elite destinadas às ordens religiosas e pelo papel subalterno que tinham nas estratégias de engrandecimento de suas respectivas famílias até ao final do século XVIII (Monteiro 2003). Seriam as mulheres ligadas à diplomacia um grupo diferenciado dentro da elite portuguesa? Seriam elas distintas de suas congêneres em outros países? O segundo passo é examinar o efeito das mudanças do Congresso de Viena e das restaurações monárquicas 
do período pós-napoleônico em Portugal e, posteriormente, no Brasil. Na literatura, há indicação de que teria ocorrido significativo declínio do salão - e o papel feminino da salonnière (Sluga 2014, 2015, 122). Será que essa tendência atingiu a mulher luso-brasileira em espaços fora da Europa? Terceiro, deve-se aprofundar o exame do papel particular de Portugal e do Brasil dentro da hierarquia simbólica de gênero do sistema internacional e como isso afetou as práticas cotidianas das mulheres envolvidas, ainda que indiretamente, em atividades diplomáticas.

\section{Referências bibliográficas}

Allen, Gemma. 2019. «The Rise of the Ambassadress: English Ambassadorial Wives and Early Modern Diplomatic Culture». The Historical Journal 62 (3): 617-638. DOI: https: / / doi.org/10.1017/S0018246X1800016X

Anastácio, Vanda. 2010. «Women and literary sociability in eighteenth-century Lisbon». In Women writing back/writing women back: transnational perspectives from the late Middle Ages to the dawn of the modern era, organizado por Anke Gilleir, Alicia Montoya and Suzanna van Dijk, 93-114. Leiden: Brill.

Anastácio, Vanda. 2011. «Alcipe e o Brasil: notas para uma investigação». In D. João VI e o oitocentismo, organizado por Tânia Maria Bessone, Gilda Santos, Ida Alves, Madalena Vaz Pinto e Sheila Hue, 259-268. Rio de Janeiro: Contra Capa/Faperj.

Anastácio, Vanda. 2017. «Women writers in an international context: was the marchioness of Alorna (1750-1839) cosmopolitan?» In Cosmopolitanism in the Portuguese-Speaking World, organizado por Francisco Bethencourt, 132-143. Leiden: Brill.

Andrade, Maria Ivone de Ornellas de. 2011. «Um salão oitocentista". Cultura 28: 203-216. DOI: https: / / doi.org/10.4000/ cultura.265

Araújo, Ana Cristina. 2018. «Narrar e silenciar o quotidiano. A correspondência de Gabriella Asinari di San Marzano Sousa Coutinho (1789-1821)". Revista Portuguesa de História 47: 269-291. DOI: https: / / doi.org/10.14195/0870-4147_47_14

Bellini, Ligia. 2007. «Vida monástica e práticas da escrita entre as mulheres em Portugal no Antigo Regime». Campus Social-Revista Lusófona de Ciências Sociais 3-4: 209218. Disponível em: https://revistas.ulusofona.pt/index.php/campussocial/article/view/ 233

Bernardino, Teresa. 1986. Sociedade e atitudes mentais em Portugal, 1777-1810. Lisboa: Imprensa Nacional-Casa da Moeda.

Capistrano de Abreu, João. 1954. Capítulos de história colonial, 1500-1800. 4. ${ }^{\text {a }}$ ed. Rio de Janeiro: Livraria Briguiet.

Carvalho, Maria Amália Vaz. 1898. Vida do duque de Palmella, D. Pedro de Souza Holstein. Volume 1. Lisboa: Imprensa Nacional.

Cavalcanti, Nireu Oliveira. 2004. O Rio de Janeiro setecentista: a vida e a construção da cidade da invasão francesa até a chegada da Corte. Rio de Janeiro: Zahar.

Cidade, Hernani, ed. 1941. Marquesa de Alorna. Inéditos. Cartas e outros escritos. Lisboa: Livraria Sá da Costa.

Conde da Carnota, e J. M. da Fonseca e Castro. 1872. Memorias do marquez de Pombal, contendo extractos dos seus escriptos e da correspondencia diplomatica inedita existente em differentes secretarias d'estado, por John Smith... traduzidas por J. M. Fonseca e Castro. Lisboa: A. M. Pereira. 
Denéchère, Yves, ed. 2004. Femmes et diplomatie. France - XXe siècle. Bruxelles: Peter Lang.

Dias, Maria Odila Leite da Silva. 1986. «A interiorização da metrópole (1808-1853)». In 1822: dimensões, organizado por Carlos Guilherme Mota, 160-186. São Paulo: Perspectiva.

Dumont, Jean, e Jean Rousset. 1739. Le Ceremonial Diplomatique des cours de l'Europe ou collection des actes, memoires et relations qui concernent les dignitez, titulatures, leurs sacres, couronnemens, mariages, batêmes, \& enterremens; les inveítitures des grands fiefs; les entrées publiques, audiences, fonctions, immunitez \& franchifes des ambassadeurs \& autres ministres publics; leurs disputes \& démêlez de préféance; et en général tout ce qui a rapport au cérémonial \& à l'etiquette. Vol. 2. Amsterdam: Chez les Janssons à Waesberge, Wetstein \& Smith, \& Z. Chatelain.

Esdaile, Charles J. 2014. Women in the Peninsular War. Norman, OK: University of Oklahoma Press.

Ferraguto, Mark. 2016. «Representing Russia: luxury and diplomacy at the Razumovsky Palace in Vienna, 1803-1815». Music and Letters 97 (3): 383-408. DOI: https://doi. org $/ 10.1093 / \mathrm{ml} /$ gcw050

Garner, Karen. 2018. Women and gender in international history: theory and practice. London: Bloomsbury Academic.

James, Carolyn. 2015. «Women and diplomacy in Renaissance Italy». In Women, diplomacy and international politics since 1500, organizado por Glenda Sluga e Carolyn James, 13-29. New York: Routledge.

James, Carolyn, and Glenda Sluga. 2015. «The long international history of women and diplomacy». In Women, diplomacy and international politics since 1500, organizado por Glenda Sluga e Carolyn James, 1-12. New York: Routledge.

Kraay, Hendrik. 2006. «Muralhas da independência e liberdade do Brasil: a participação popular nas lutas políticas (Bahia, 1820-25)». In A independência brasileira: novas dimensões, organizado por Jurandir Malerba, 303-342. Rio de Janeiro: FGV.

Kühnel, Florian. 2017. "Minister-like Cleverness, Understanding and Influence on Affairs": Ambassadresses in Everyday Business and Courtly Ceremonies at the Turn of the Eighteenth Century.» In Practices of diplomacy in the early modern world c. 14101800, organizado por Tracey Amanda Sowerby e Jan Hennings, 130-146. London: Routledge.

Langsdorff, George H. von. 1997. Os diários de Langsdorff. 3 vols. Campinas; Rio de Janeiro: Associação Internacional de Estudos Langsdorff; Casa de Oswaldo Cruz; Editora Fiocruz.

Luccock, John. 1820. Notes on Rio de Janeiro, and the southern parts of Brazil; taken during a residence of ten years in that country, from 1808 to 1818. London: S. Leigh.

Malerba, Jurandir. 2000. A corte no exílio. Civilização e poder no Brasil às vésperas da Independência (1808 a 1821). São Paulo: Companhia das Letras.

McCarthy, Helen. 2015. «Gendering diplomatic history: women in the British diplomatic service, circa 1919-1972». In Women, diplomacy and international politics since 1500, organizado por Glenda Sluga e Carolyn James, 167-181. New York: Routledge.

McMillan, James F. 2000. France and women, 1789-1914: gender, society and politics. London: Routledge.

Meneses, Antônio Teles da Silva Caminha. 1917. "Correspondência do Marquez de Resende». Revista do Instituto Histórico e Geográfico Brasileiro 80 (1): 155-525.

Ministério das Relações Exteriores. 1972 [1922]. Arquivo diplomático da Independência. Volume IV. Áustria - Estados da Allemanha. Rio de Janeiro: Ministério das Relações Exteriores. 
Monteiro, Nuno Gonçalo. 2003. «17th and 18th century Portuguese Nobilities in the European Context: A historiographical overview». E-Journal of Portuguese History 1 (1). Disponível em: https: / / digitalis.uc.pt/en/node/84951

Monteiro, Nuno Gonçalo, Pedro Cardim e David Felismino. 2005. «A diplomacia portuguesa no Antigo Regime. Perfil sociológico e trajectórias.» In Optima Pars: elites ibero-americanas do Antigo Regime, organizado por Nuno Gonçalo Monteiro, Pedro Cardim e Mafalda Soares da Cunha, 277-337. Lisboa: ICS.

Mori, Jennifer. 2015. «How Women Make Diplomacy: The British Embassy in Paris, 18151841». Journal of Women's History 27 (4): 137-159. DOI: https:// doi.org/10.1353/ jowh.2015.0042

Moser, Friedrich Carl. 1752. L'ambassadrice et ses droits. Berlin: É. de Bourdeaux.

Pereira, Angelo. 1956. D. João VI principe e rei. A Independência do Brasil. Lisboa: Empresa Nacional de Publicidade.

Pins, Jean de. 1976. «Un grand ministre Portugais au temps de Napoleon: le Comte de Barca (1754-1817)». Revue de l'Institut Napoléon 132 (1): 103-140.

Pins, Jean de. 1984. Sentiment et diplomatie d'après des correspondances franco-portugaises: contribution a l'histoire des mentalités au début du XIXe siècle. Paris: Fondation Calouste Gulbenkian.

Prestage, Edgar, e Edgar Azevedo, orgs. 1920. Correspondência diplomática de Francisco de Sousa Coutinho durante sua embaixada em Holanda. Volume 1 -1643-1646. Coimbra: Imprensa da Universidade. Disponível em https: / / archive.org/ details / correspondncia00sousuoft/page/n7

Priori, Mary del. 2008a. Condessa de barral: a paixão do Imperador. Rio de Janeiro: Objetiva.

Priori, Mary del. 2008b. «Um poeta no tempo de D. João VI». Revista Brasileira 54: 125-162. Disponível em http: / / www.academia.org.br/sites/ default/ files / publicacoes / arquivos/revista-brasileira-54.pdf

Roosen, William. 1978. «A new way of looking at early modern diplomacy: quantification.» Proceedings of the Western Society for French History 5: 1-16.

Silva, Andrée Mansuy-Diniz. 2006. Portrait d'un homme d'Etat, D Rodrigo de Souza Coutinho, Comte de Linhares, 1755-1812. II. 2 vols. Paris: Fundação Calouste Gulbenkian; Centre culturel Calouste Gulbenkian.

Silva, Maria Beatriz Nizza. 1993. Vida privada e quotidiano no Brasil. Na época de D. Maria I e D. João VI. Lisboa: Editorial Estampa.

Sluga, Glenda. 2014. «On the Historical Significance of the Presence, and Absence, of Women at the Congress of Vienna, 1814-1815». L'Homme 25 (2): 49-62. DOI: https:/ / doi.org/10.7788/ figurationen-2014-0205

Sluga, Glenda. 2015. «Women, diplomacy and international politics, before and after the Congress of Vienna». In Women, diplomacy and international politics since 1500, organizado por Glenda Sluga e Carolyn James, 120-136. New York: Routledge.

Sobral Neto, Margarida. 2001. «O papel da mulher na sociedade portuguesa setecentista». In Diálogos oceânicos: Minas Gerais e as novas abordagens para uma história do império ultramarino português, organizado por Júnia Ferreira Furtado, 25-44. Belo Horizonte: UFMG.

Tostes, Vera Lúcia Bottrel. 2008. «O Rio de Janeiro no tempo de D. João VI.» Revista Brasileira 54: 263-276. Disponível em http:/ / www.academia.org.br/sites/default/files/ publicacoes / arquivos / revista-brasileira-54.pdf

Towns, Ann E. 2010. Women and states: norms and hierarchies in international society. Cambridge: Cambridge University Press. 
Walsh, R. 1831. Notices of Brazil in 1828 and 1829. 2 vols. Boston; New York: Richardson G. \& C. \& H. Carvill.

Zalewski, Marysia. 2010. «Feminist international relations: making sense...» In Gender matters in global politics: a feminist introduction to international relations, organizado por Laura J. Shepherd, 28-43. London: Routledge.

Rogério de Souza Farias. Doutor pelo Instituto de Relações Internacionais da Universidade de Brasília. Como Especialista em Políticas Públicas e Gestão Governamental do Ministério do Planejamento, Orçamento e Gestão (MPOG), atuou no Ministério do Desenvolvimento, Indústria e Comércio Exterior e na Escola Nacional de Administração Pública (ENAP). Ganhou o Concurso de Teses da Associação Brasileira de Relações Internacionais em 2013. Foi visiting scholar do Lemann Institute for Brazilian Studies (2013-2017) e associate do Center for Latin American Studies da Universidade de Chicago (2014-2017).

Endereço eletrônico: rofarias@gmail.com

Artigo recebido a 29 de junho e aceite para publicação a 14 de setembro de 2019. 